\title{
Teens Impulsively React rather than Retreat from Threat
}

\author{
Michael Dreyfuss $^{a} \quad K^{2}$ ristina Caudle ${ }^{a} \quad$ Andrew T. Drysdale ${ }^{a} \quad$ Natalie E. Johnston ${ }^{a}$ \\ Alexandra O. Cohen ${ }^{a}$ Leah H. Somerville ${ }^{b}$ Adriana Galván ${ }^{c}$ Nim Tottenham ${ }^{c}$ \\ Todd A. Hared B.J. Casey ${ }^{\mathrm{a}}$ \\ a Sackler Institute, Department of Psychiatry, Weill Cornell Medical College, New York, N.Y., b Department of \\ Psychology, Harvard University, Cambridge, Mass., and ' Department of Psychology, University of California Los \\ Angeles, Los Angeles Calif., USA; ' Laboratory for Social and Neural Systems Research, Department of Economics, \\ University of Zurich, Zurich, Switzerland
}

\section{Key Words}

Adolescence · Fear · Impulsivity · Limbic circuitry ·

Orbitofrontal cortex $\cdot$ Medial prefrontal cortex

\begin{abstract}
There is a significant inflection in risk taking and criminal behavior during adolescence, but the basis for this increase remains largely unknown. An increased sensitivity to rewards has been suggested to explain these behaviors, yet juvenile offences often occur in emotionally charged situations of negative valence. How behavior is altered by changes in negative emotional processes during adolescence has received less attention than changes in positive emotional processes. The current study uses a measure of impulsivity in combination with cues that signal threat or safety to assess developmental changes in emotional responses to threat cues. We show that adolescents, especially males, impulsively react to threat cues relative to neutral ones more than adults or children, even when instructed not to respond. This adolescent-specific behavioral pattern is paralleled by enhanced activity in limbic cortical regions implicated in the detection and assignment of emotional value to inputs and in the subsequent regulation of responses to them when successfully suppressing impulsive responses to
\end{abstract}

threat cues. In contrast, prefrontal control regions implicated in detecting and resolving competing responses show an adolescent-emergent pattern (i.e. greater activity in adolescents and adults relative to children) during successful suppression of a response regardless of emotion. Our findings suggest that adolescence is a period of heightened sensitivity to social and emotional cues that results in diminished regulation of behavior in their presence.

(C) 2014 S. Karger AG, Basel

\section{Introduction}

Adolescents commit more crimes per capita than children or adults in the USA [1] and in nearly all industrialized cultures [2]. Their proclivity toward incentives [3,4] and risk taking [5-8] has been suggested to underlie the inflection in criminal activity observed during this time. Yet heightened sensitivity to incentives and risk taking are only part of the equation, as criminal behaviors often occur in emotionally charged situations of negative valence. Does negative emotional information impact self-

M.D. and K.C. contributed equally to this work.

\section{KARGER}

E-Mail karger@karger.com

www.karger.com/dne
(C) 2014 S. Karger AG, Basel

0378-5866/14/0364-0220\$39.50/0
B.J. Casey, $\mathrm{PhD}$

Sackler Institute for Developmental Psychobiology

Weill Cornell Medical College, 1300 York Avenue, Box 140

New York, NY 10065 (USA)

E-Mail bjc2002@med.cornell.edu 
control differently across development? Previous work has shown that positive emotional cues lead to poorer self-control in adolescents relative to children and adults [3], but do negative emotional cues also lead to poor impulse control? The current study tests whether adolescents are more impulsive relative to adults or children when there is a signal of potential threat, using a measure of impulsivity in combination with cues that signal threat (e.g. a frightened face) relative to neutral ones (calm face) and examines potential mechanisms for developmental differences in behavior.

The fight-or-flight response is a physiological reaction to perceived threat [9]. Fearful faces are a reliable indicator of threat in the immediate environment [10], evoking a well-defined neural response $[11,12]$. Negatively valenced stimuli such as fearful faces generally inhibit behavior, slowing response times and inhibiting motor responses in various tasks [13-15]. Adolescents, however, show difficulty suppressing attention and actions toward emotional stimuli even when irrelevant to the task at hand $[16,17]$. This relative lack of cognitive control in the presence of emotional and motivational cues may underlie the behavioral risks that are characteristic of adolescence [18].

Prior work suggests that diminished self-control during adolescence may result from competition between limbic and control circuitry [17-20]. A combination of evidence from human imaging [3, 21-25], postmortem [26] and animal [27, 28] studies of regional brain changes over the course of development indicate that limbic and prefrontal circuitry interact differentially across development [29]. Specifically, limbic circuitry is thought to develop earlier than control circuitry as a result of evolutionary pressure and changes in gonad hormone levels that impact limbic structures. This developmental imbalance is suggested to result in a greater influence of limbic than prefrontal regions on behavior during adolescence. This pattern is in contrast to that observed in adulthood when these circuits have matured or in childhood when they are still developing.

The current study uses a A go/no-go paradigm to measure impulsivity in combination with cues that signal threat or safety (fearful or calm facial expressions) to assess developmental changes in emotional responses to such cues, their influence on behavior and their neurobiological correlates. In previous work using the same task and overlapping sample, we have shown a heightened sensitivity to emotional cues during adolescence. In the first study [30] we showed longer response latencies to negative (fear faces) relative to positive (happy faces) emotional cues across ages but adolescent-specific increases in amygdala activity when having to respond (go) to fear faces. In a second study [3], we focused on the ability to withhold a response to positive cues, focusing solely on happy no-go trials and showed that adolescents made more false alarms to happy cues than to neutral cues compared to children and adults. This pattern was paralleled by greater ventral striatal activity in adolescents relative to children and adults. Finally, recent reports by other laboratories have noted decrements in behavioral performance on cognitive control tasks in the presence of negatively valenced stimuli versus neutral stimuli in adolescents relative to children or adults $[15,16]$.

In the current study, expanding on these previous adolescent-specific findings toward emotionally valenced stimuli, we test for developmental differences in brain and behavior when required to suppress responses to cues of potential threat. Second, we explore individual differences in brain activity associated with overall behavioral performance. Finally, we explore possible sex differences in behavior and brain responses to cues of potential threat.

\section{Methods}

Subjects

A total of 80 participants between the ages of 6 and 27 years were scanned using functional magnetic resonance imaging (fMRI). Data from 23 participants were excluded due to poor overall accuracy (mean no-go accuracy $<70 \%, \mathrm{n}=9$ ), too much head motion ( $>2 \mathrm{~mm}$ translational or $2^{\circ}$ rotational motion within a run, $\mathrm{n}=12$ ) or technical problems $(\mathrm{n}=2)$, resulting in data from 57 usable subjects ( 27 females) in all reported analyses. Participants were grouped into child (aged 6-12 years, $\mathrm{n}=18,10$ male), adolescent (aged 13-17 years, $\mathrm{n}=19,10$ male) and adult (18 years or older, $n=20,10$ male) age groups. Data from this sample have been published previously on a different subset of the data $[3,30]$. All participants provided informed written consent (parental consent and subject assent for children and adolescents) approved by the Institutional Review Board of Weill Cornell Medical College.

\section{Behavioral Paradigm}

Participants completed six runs of a go/no-go task $[3,30]$ using fearful, happy and calm facial expressions as target (go) and nontarget (no-go) stimuli (fig. 1a). Within each run, two types of facial emotions were presented, one serving as the target (go) stimulus, to which they were instructed to press a button, and the other serving as a nontarget (no-go) stimulus, for which they were instructed to withhold a button press. Facial expressions were pseudorandomized across the run to control for presentation order, and all combinations of expression were used as both targets and nontargets, resulting in a 2 (response: go, no-go) $\times 3$ (emotion: fear, calm, happy) factorial design. Prior to each run, participants were instructed as to which expression served as the target (go) stimulus and that they should respond with a button press only to that ex- 


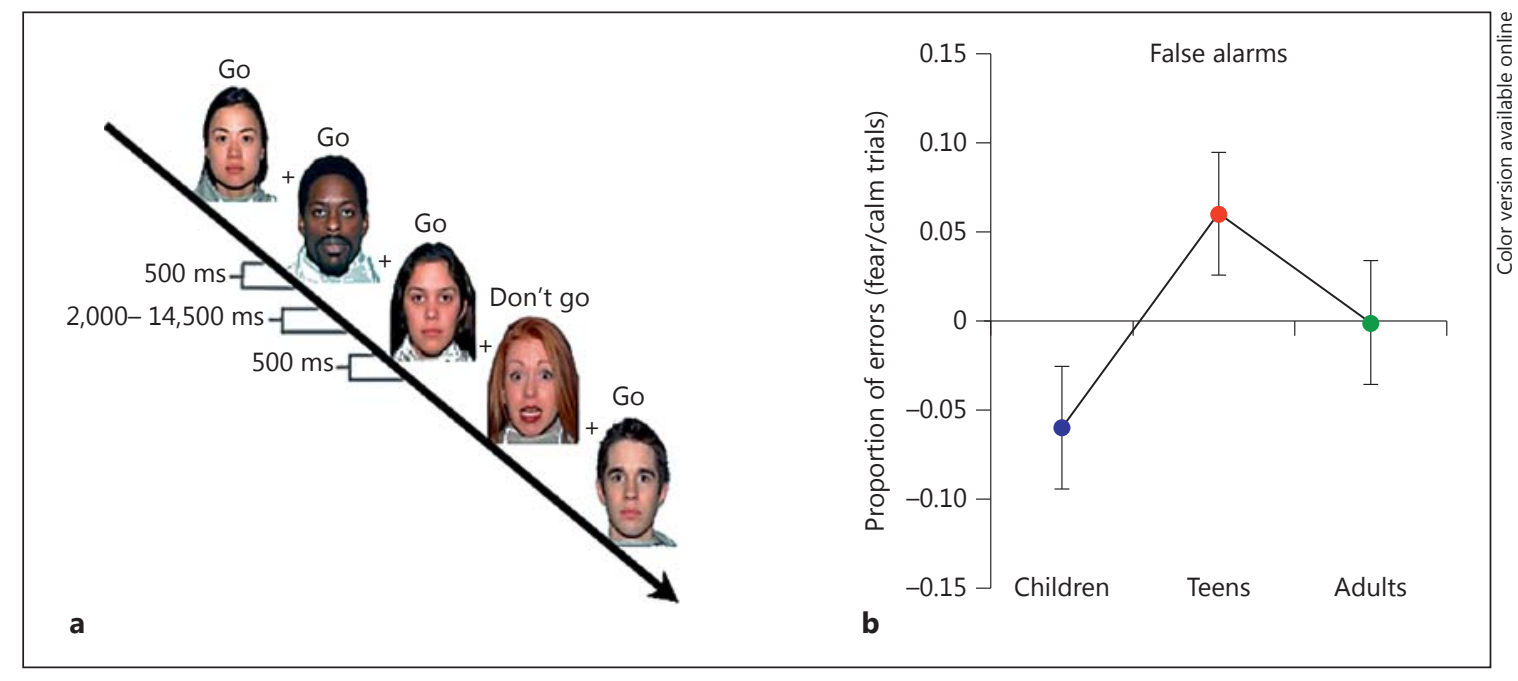

Fig. 1. Development of impulse control to threat cues. a The emotional go/no-go task illustrating 5 trials with calm faces as the target stimuli, for which participants should go by pressing a button. Fearful faces are the nontarget (no-go) stimuli, to which participants should withhold a button press. Each face was displayed for

pression. Participants were also instructed to respond as fast as possible but to try to avoid making errors. The present report focuses specifically on the analysis of fear no-go trials relative to calm no-go trials. Previously published work on this task focused on no-go trials to happy facial expressions [3] and go trials to fearful facial expressions [30].

\section{Stimuli and Apparatus}

The stimuli consisted of fearful, happy and calm faces from the NimStim set of facial expressions [31]. We used calm faces (mildly pleasant neutral faces) because we [32] and others [33, 34] have shown that developmental populations may perceive neutral faces as negative. The task was programmed using E-Prime software and presented to subjects on an overhead liquid crystal display panel integrated with the IFIS-SA system (fMRI Devices Corporation, Waukesha, Wisc., USA). Button responses and reaction times were logged using E-Prime software integrated with the IFIS system.

\section{Task Parameters}

The data were acquired in six functional imaging runs that combined each emotion (happy, calm and fear) and response (go and no-go; fig. 1) using a rapid event-related design. On each trial, a face appeared for $500 \mathrm{~ms}$ followed by a jittered intertrial interval of between 2 and $14.5 \mathrm{~s}$ (mean $5.2 \mathrm{~s}$ ) during which participants were presented with a fixation crosshair. A total of 48 trials were presented per run in pseudorandomized order (36 go and 12 nogo). A total of 24 no-go trials and 72 go trials were acquired for each expression type.

\section{Image Acquisition}

Participants were scanned with a General Electric Signa 3.0-T fMRI scanner (General Electric Medical Systems, Milwaukee, Wisc., USA) and quadrature head coil. A high-resolution, T1-
$500 \mathrm{~ms}$ followed by a variable intertrial interval. b False alarms (dark gray line) to fear relative to calm no-go trials show an adolescent-specific pattern of more commission errors for adolescents than either children $\left(t_{35}=2.79, \mathrm{p}<0.009\right)$ or adults $\left(t_{37}=2.30, \mathrm{p}<\right.$ $0.03)$.

weighted anatomical scan $(256 \times 256$ in-plane resolution, $240-\mathrm{mm}$ field of view, 124 1.5-mm slices) was acquired for each subject for transformation and localization of data to Talairach grid space. A spiral in and out sequence [35] was used to acquire functional imaging data (repetition time $=2,500 \mathrm{~ms}$, echo time $=30 \mathrm{~ms}$, field of view $=200 \mathrm{~mm}$, flip angle $=90$, skip 0,64 $\times 64$ matrix). In all, 34 4-mm-thick coronal slices $(3.125 \times 3.125 \mathrm{~mm}$ resolution $)$ covering the entire brain except for the posterior portion of the occipital lobe were acquired per repetition time.

\section{Behavioral Analysis}

Behavioral data from the emotional go/no-go task were analyzed for false alarms (incorrect presses to a 'no-go' stimulus) to fear and calm cues. Errors were calculated as a difference score between errors to fear nontargets relative to calm nontargets to isolate the effects of negative valence from the overall error rate. Error rates were compared between age groups (children, adolescents and adults). A positive value represents a greater proportion of errors to nontarget fear faces than calm faces, while a negative value represents the inverse. Mean reaction times and hit rates have been reported elsewhere [30]. A two-way ANOVA was performed with age group and sex as the between-subject variables and a difference score between errors to fear nontargets and errors to calm nontargets as the dependent variable of interest.

\section{Imaging Analysis}

Imaging data processing and analyses were performed using AFNI (analysis of functional neuroimages) software [36]. Functional imaging data were slice-time corrected, realigned within and across runs to correct for head movement, coregistered with each participant's high-resolution anatomical scan, scaled to percent signal change units, and smoothed with a 6-mm FWHM gaussian kernel. A general linear model (GLM) analysis was performed on 
each subject to characterize task effects with task regressors (calm/ go, calm/no-go, happy/go, happy/no-go, fear/go, fear/no-go, errors), convolved with a gamma-variate hemodynamic response function. Separate regressors were created for correct go and no-go trials, broken down by emotion (errors were grouped and modeled separately with insufficient numbers to analyze separately). Only correct fear and calm trials were considered of interest and included in the second-level analysis.

We modeled the effects of response (go vs. no-go), age group (child, adolescent or adult) and emotion (fear or calm) on brain activity using a linear mixed-effects model [37]. Parameter estimate $(\beta)$ maps representing task effects were then transformed into the standard coordinate space of Talairach and Tournoux [38] (1988) by applying the warping parameters obtained from the transformation of each subject's high-resolution anatomical scan. Talairach-transformed parameter estimate maps were resampled to a resolution of $3 \times 3 \times 3 \mathrm{~mm}$. A group linear mixed-effects model was performed to identify functional regions of interest (ROIs) implicated in the interaction of response, age group and emotion. Imaging findings considered statistically significant exceeded whole-brain correction for multiple comparisons to preserve an alpha $<0.05$ by using a $\mathrm{p}$ value/cluster size combination stipulated by Monte Carlo simulations run in the AlphaSim program within AFNI. Off-line analyses were conducted in SPSS Statistics 17.0 software (SPSS, Chicago, Ill., USA). Beta values were extracted from whole-brain-corrected ROIs (drawing a 5-mm sphere around the peak voxel in each region) and submitted to offline post hoc analyses with SPSS.

\section{Control Analyses}

All imaging analyses were based on correct no-go trials. As task performance was significantly different between age groups, a second analysis was conducted to verify that the observed developmental effects were not due to less power in one age group relative to another. First-level GLMs were estimated in which number of correct trials were equated for all participants across conditions (fear/go, fear/no-go, calm/go, calm/no-go), using the lowest mean number of correct trials of all age groups (calm no-go trials in children; mean $=17$ out of 24 possible, or $70 \%$ mean accuracy). New regressors were generated by randomly selecting 17 (of 24) trials per condition for inclusion. All other trials were modeled as separate regressors that were not further examined. Beta values were extracted from the 17-trial regressors using the previously defined ROIs, tested for replication, and reported in Results.

\section{Results}

\section{Behavioral Results}

The 2-way ANOVA showed a main effect of age group on false alarm rates to fear relative to calm nontargets $\left(\mathrm{F}_{2,59}=8.58, \mathrm{p}<0.001\right)$, but no main effect of $\operatorname{sex}\left(\mathrm{F}_{1,51}=\right.$ $0.05, \mathrm{p}>0.85)$ or interaction with sex $\left(\mathrm{F}_{2,51}=0.27, \mathrm{p}>\right.$ $0.77)$. Post hoc $t$ tests showed that adolescents made more false alarms to fear nontargets in comparison to calm nontargets than either children $\left(\mathrm{t}_{35}=2.79, \mathrm{p}<0.009\right)$ or adults $\left(\mathrm{t}_{37}=2.30, \mathrm{p}<0.03\right.$; fig. $\left.1 \mathrm{~b}\right)$.

Teens Impulsively React rather than Retreat from Threat

\section{Imaging Results}

The whole-brain age group $(3) \times$ response $($ go/nogo) $\times$ emotion (fear, calm) linear mixed-effects model revealed 7 ROIs (see table 1). Given the behavioral results we performed post hoc tests on beta values extracted from each whole-brain-corrected ROI to determine if teens differed from adults and from children in these regions. When we tested each region to determine whether significant variance could be attributed to adolescent-specific differences in response to fear relative to calm nontargets, two patterns emerged (see fig. 2): (1) adolescent-specific effects were of greater activity in adolescents compared to children or adults on correct threat no-go trials relative to calm no-go trials and (2) adolescentemergent effects of adolescents and adults activated this region more than children on correct threat no-go trials. The left orbitofrontal cortex (LOFC) and medial prefrontal cortex (mPFC) showed adolescent-specific effects. Although the striatum showed a similar developmental pattern post hoc tests did not reach significance between age groups (adolescents vs. children: $\mathrm{p}=0.09$ and adolescents vs. adults: $\mathrm{p}=0.11)$. The right inferior frontal gyrus (RIFG), right anterior cingulate cortex (RACC) and left premotor cortex showed adolescent-emergent effects. Our control analysis, equating power across age groups and conditions, revealed similar patterns of activity, but to a lesser degree given less overall power of the analysis. However, the LOFC maintained a robust pattern of activity across analyses (adolescents vs. children: $\mathrm{t}_{35}=2.74, \mathrm{p}<$ 0.01 and adolescents vs. adults: $\mathrm{t}_{37}=2.27, \mathrm{p}<0.03$ ).

\section{Sex Differences}

We performed exploratory analyses to test for sex differences within the three adolescent-specific findings (i.e. false alarm rates and OFC and mPFC activity to threat nontargets relative to calm nontargets). These exploratory analyses revealed that males rather than females appeared to be driving the inflection in false alarms to threat nontargets during adolescence (fig. $3 \mathrm{a}$ ). Independent $\mathrm{t}$ tests revealed that in males, adolescents made more false alarms than children $\left(\mathrm{t}_{18}=2.28, \mathrm{p}<0.04\right)$ or adults $\left(\mathrm{t}_{18}=\right.$ $2.96, \mathrm{p}<0.009)$ and showed a similar pattern in the activation of the OFC, a region implicated in the regulation of approach-related behavior (adolescents vs. children: $\mathrm{t}_{18}=2.31, \mathrm{p}<0.04 ;$ adolescents vs. adults: $\mathrm{t}_{18}=2.39, \mathrm{p}<$ 0.03; fig. 3b).

In contrast, the female age groups did not differ from one another in performance (children vs. adolescents: $\mathrm{p}=$ 0.44 and adolescents vs. adults: $\mathrm{p}=0.07$ ) or in OFC activity (children vs. adolescents: $\mathrm{p}=0.19$ and adolescents vs. 


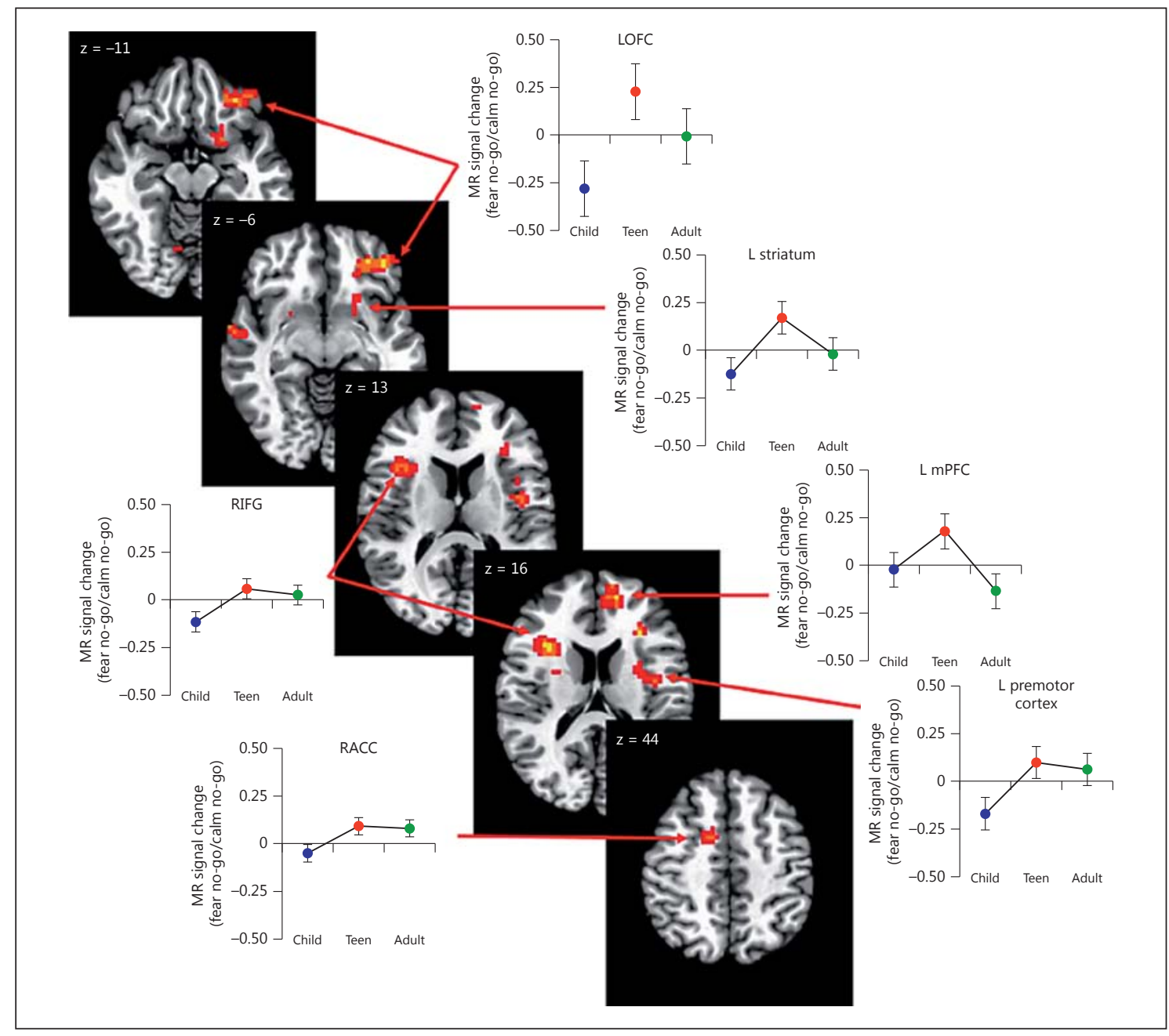

Fig. 2. Adolescent-specific and adolescent-emergent brain regions. Representative axial images and beta weights for those regions showing an age effect on correct fear no-go trials relative to calm ones from the whole-brain-corrected age $(3) \times$ response $(2) \times$ emotion (2) interaction. $\mathrm{L}=\mathrm{Left}$. Adolescent-specific effects on correct fear relative to calm no-go trials were found in contrasts between adolescents relative to children and adults together in the LOFC $\left(\mathrm{t}_{55}=2.612, \mathrm{p}<0.012\right)$ and left mPFC $\left(\mathrm{t}_{55}=2.832, \mathrm{p}<0.006\right)$ Adolescent-emergent effects were found in activation contrasts in children relative to adolescents and adults together on correct fear relative to calm no-go trials in the RIFG $\left(\mathrm{t}_{55}=2.503, \mathrm{p}<0.02\right)$, RACC $\left(t_{55}=2.44, \mathrm{p}<0.02\right)$ and left premotor cortex $\left(\mathrm{t}_{55}=3.658\right.$, $\mathrm{p}<0.001)$.

Table 1. ROIs (Talairach) for the interaction of age group $\times$ emotion $\times$ response type

\begin{tabular}{clccc}
\hline Voxels, $\mathrm{n}$ & Region & Brodmann's area & Coordinates (peak) & F value \\
\hline 193 & RIFG & 45 & $32,17,18$ & 8.41 \\
104 & LOFC & 11 & $-38,41,-7$ & 8.86 \\
78 & L mPFC & 9 & $-8,53,24$ & 7.95 \\
72 & L premotor & 6 & $-41,2,7$ & 8.68 \\
58 & L striatum & & $-20,8,-10$ & 6.59 \\
56 & L motor/premotor & 4,6 & $-14,-8,63$ & 7.74 \\
51 & RACC & 32 & $11,2,45$ & 6.86 \\
\hline
\end{tabular}

Results are whole-brain corrected (alpha $=0.05,47$ voxels). $\mathrm{L}=$ Left. 


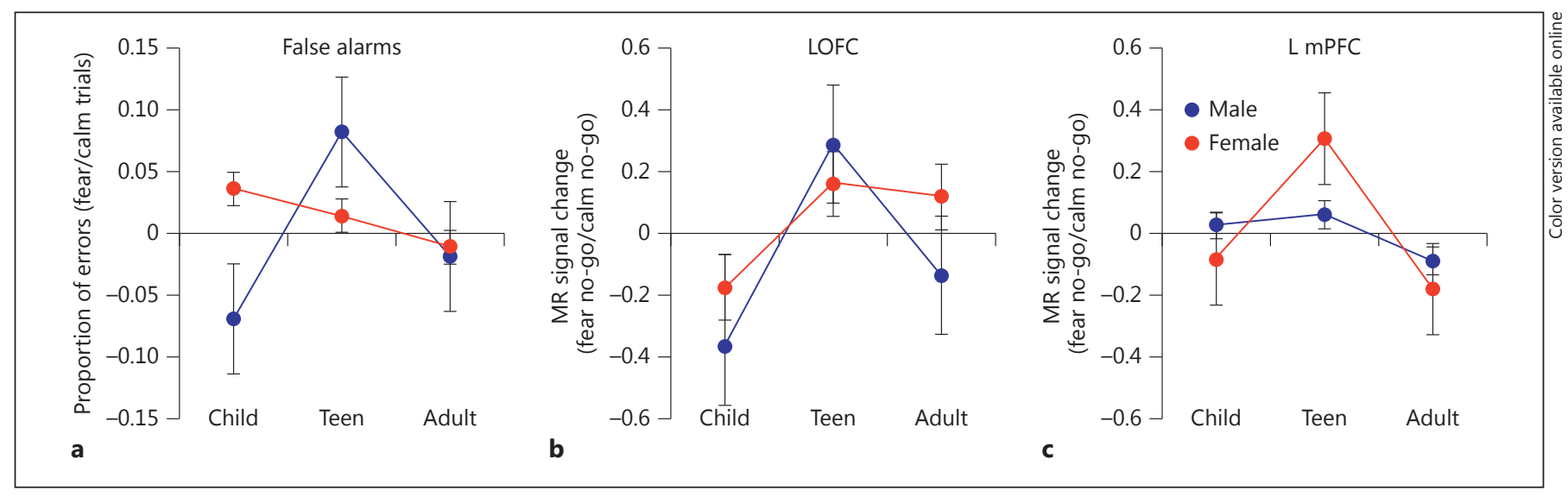

Fig. 3. Sex Differences in behavior and limbic activity by age group. a Difference score in number of false alarms to fear no-go trials relative to calm no-go trials by age group and sex. b Beta weights

adults: $p=0.76)$. Rather, adolescent females showed greater activity in the $\mathrm{MPFC}$, a region implicated in the regulation of avoidance-related behavior (fig. 3 c; children vs. adolescents $\mathrm{t}_{15}=2.53, \mathrm{p}<0.03$ and adolescents vs. adults $\left.\mathrm{t}_{17}=2.65, \mathrm{p}<0.02\right)$. Males did not differ across age groups in this region (children vs. adolescents: $\mathrm{p}=0.79$ and adolescents vs. adults: $\mathrm{p}=0.26$ ).

\section{Discussion}

Prior research has focused almost exclusively on how incentives and positive social cues lead to impulsive decisions during adolescence to help explain inflections in risk taking and criminal behavior during this period $[3,8$, $25,39]$. The current study examined the effect of threat cues on impulse control and the underlying neural circuitry in adolescents. We found that just as positive cues can lead to more impulsive responses by adolescents relative to children and adults [3], so too can threat cues. This adolescent-specific inflection in false alarms to threat cues was paralleled by marked increases in limbic prefrontal (orbitofrontal and medial prefrontal) regions, implicated in regulating emotional and behavioral responses, particularly in the case of threat-related stimuli.

In contrast to the adolescent-specific effects in limbic prefrontal regions, prefrontal control circuitry implicated in detecting and resolving conflict between two competing responses showed an adolescent-emergent pattern [4042]. Specifically, activity in RIFG and RACC increased from childhood to adolescence and then plateaued. These findings are consistent with developmental studies show-

Teens Impulsively React rather than

Retreat from Threat for OFC to correct fear no-go trials relative to calm no-go trials by age group and sex. c Beta weights for $\mathrm{mPFC}$ to correct fear no-go trials relative to calm no-go trials by age group and sex. $\mathrm{L}=\mathrm{Left}$.

ing that the ability to ignore irrelevant information on cognitive tests like the flanker and go/no-go tasks reaches maturity levels roughly by adolescence [16, 41, 43-45].

The difficulty of adolescents in suppressing attention and actions specifically toward negatively valenced information in the current study is a pattern that is emerging in the developmental literature $[15,16]$. This diminished performance in adolescents is not observed in tasks demanding suppression of attention or actions toward neutral information $[3,16]$. One explanation for the results reported here may be a failure of adolescents to withhold responses to any emotional stimuli [41]. However, recent work suggests that the actions of adolescents may be disrupted more easily by negative than positive emotional information [15] and differential patterns of activity have been shown for positive and negative emotional stimuli $[3,30]$. Together these findings suggest that changes in behavior and limbic circuitry during adolescence coincide with a heightened sensitivity to emotional cues that may cause them to impulsively react rather than retreat from cues of potential threat.

Theoretical and empirical accounts for this diminished performance during adolescence fall along two lines of evidence. The first is evidence of regional brain development with lateral PFC continuing to reach structural and functional maturity throughout the adolescent years $[3,23]$ and the connections between subcortical and cortical structures continuing to strengthen $[46,47]$. Given the role of the lateral PFC in the regulation of behavior, immature connections between it and limbic structures might reduce the capacity to exert cognitive control, particularly in emotionally salient contexts $[15,16]$. The second line of evi- 
dence comes from neuroendocrinology studies, showing an influx of hormones during puberty thought to sensitize functional properties of certain brain circuits [19, 48, 49], potentially resulting in adolescent-specific enhanced signaling in limbic regions that are especially sensitive to hormonal changes. Thus the heightened recruitment of regulatory prefrontal circuitry when successfully suppressing attention to emotional cues may suggest an adolescentspecific hyper-responsiveness to emotional cues that requires greater recruitment of regulatory regions. Together, these observations suggest that diminished regulation of sensitized limbic circuits may heighten the detection of, and response to, salient social cues during adolescence, even when irrelevant for goal-directed behavior.

An elevated sensitivity or reaction to threat cues during adolescence may have important implications for understanding risky or criminal-related behaviors under a heightened sense of threat. These behaviors have been reported to be higher in males than females [50-52]. So how might the adolescent-specific behavioral and imaging findings relate to sex differences observed in real world behavior? Although there was no main effect of, or interaction with, sex in the 2-factor ANOVA, exploratory independent $t$ tests revealed that males rather than females appeared to be driving the inflection in false alarms to threat cues during adolescence. Specifically, male adolescents made more false alarms than either male children or adults and showed a parallel increased activation pattern in the OFC when successfully inhibiting a response, a region implicated in the regulation of approach-related behavior. In contrast, female adolescents did not significantly differ from female children or adults in their performance or in activity in this region. Rather, they showed greater activity in the $\mathrm{mPFC}$, a region implicated in regulation of avoidance-related behavior. Adolescent males did not significantly differ from children or adults in this region. These exploratory results suggest a possible double dissociation between adolescent males and females in cortical limbic activity related to impulsively reacting and retreating from cues of potential threat, respectively, that warrants further investigation in a larger sample. In addition, a number of other factors, not specifically measured in this study, may have contributed to the observed age and sex differences such as discrepancies between the sexes in pubertal onset, pubertal stage and quality and/or lack of sleep.

The present study demonstrates that impulsive behavior during adolescence is as likely to occur in the presence of threat as reward cues. We show that rather than retreating or withholding a response to threat cues, adolescents are more likely than children or adults to impulsively react to them, even when instructed not to respond. This developmental pattern is mirrored by adolescentspecific changes in limbic cortical circuitry implicated in the detection and assignment of emotional value to inputs and in the subsequent regulation of responses to them [53-56]. Clearly more research will be required to specify the impact of threat cues on adolescent behavior. Nonetheless, these findings may have significant implications for conditions in which adolescents impulsively react and put themselves and others in harm's way.

\section{Acknowledgments}

The authors thank Doug Ballon, Gary Glover, Henning Voss, and the resources and the staff at the Biomedical Imaging Core and Citigroup Biomedical Imaging Center at Weill Cornell Medical College for their assistance in collecting these data. This work was supported by the National Institute of Health grants P50MH079513 (B.J.C.), R01DA018879 (B.J.C.) and F31MH073265 (T.A.H.), MSTP training grant GM07739 (M.D. and A.T.D.), NSRA vision training grant 5T32EY007138-20 (N.E.J.) and by the MacArthur Law and Neuroscience Network.

\section{References}

1 Snyder H: Arrest in the United States, 19902010. Washington, US Department of Justice, 2012.

2 Steffensmeier DJ, Allan EA, Harer MD, Streifel C: Age and the distribution of crime. Am J Sociol 1989;94:803-831.

-3 Somerville LH, Hare T, Casey BJ: Frontostriatal maturation predicts cognitive control failure to appetitive cues in adolescents. J Cogn Neurosci 2011;23:2123-2134.

4 Steinberg L, Albert D, Cauffman E, Banich M, Graham S, Woolard J: Age differences in sensation seeking and impulsivity as indexed by behavior and self-report: evidence for a dual systems model. Dev Psychol 2008;44:17641778 .

5 Weller JA, Levin I, Denburg N: Trajectory of risky decision making for potential gains and losses from ages 5 to 85. J Behav Decis Making 2010;24:331-334.

-6 Paulsen D, Platt ML, Huettel SA, Brannon EM: Decision-making under risk in children, adolescents, and young adults. Front Psychol 2011;2:72.

7 Harbaugh W, Krause K, Vesterlund L: Risk attitudes of children and adults: choices over small and large probability gains and losses. Exp Econ 2002;5:53-84.

8 Chien J, Albert D, O’Brien L, Uckert K, Steinberg L: Peers increase adolescent risk taking by enhancing activity in the brain's reward circuitry. Dev Sci 2011;14:F1-F10.

9 LeDoux JE: The Emotional Brain. New York, Simon \& Schuster, 1996.

10 Davis FC, Somerville LH, Ruberry EJ, Berry $\mathrm{AB}$, Shin LM, Whalen PJ: A tale of two negatives: differential memory modulation by threat-related facial expressions. Emotion 2011;11:647-655. 
$>11$ Whalen PJ, Rauch SL, Etcoff NL, McInerney SC, Lee MB, Jenike MA: Masked presentations of emotional facial expressions modulate amygdala activity without explicit knowledge. J Neurosci 1998;18:411-418.

-12 Sagaspe P, Schwartz S, Vuilleumier P: Fear and stop: a role for the amygdala in motor inhibition by emotional signals. Neuroimage 2011;55:1825-1835.

13 MacLeod CM: Half a century of research on the Stroop effect: an integrative review. Psychol Bull 1991;109:163-203.

- 14 Simpson JR, Ongür D, Akbudak E, Conturo TE, Ollinger JM, Snyder AZ, Gusnard DA, Raichle ME: The emotional modulation of cognitive processing: an fMRI study. J Cogn Neurosci 2000;12(suppl 2):157-170.

15 Cohen-Gilbert JE, Thomas KM: Inhibitory control during emotional distraction across adolescence and early adulthood. Child Dev 2013;84:1954-1966.

16 Grose-Fifer J, Rodrigues A, Hoover S, Zottoli T: Attentional capture by emotional faces in adolescence. Adv Cogn Psychol 2013;9:8191.

17 Casey BJ, Jones RM, Hare TA: The adolescent brain. Ann NY Acad Sci 2008;1124:111-126.

18 Steinberg L: A social neuroscience perspective on adolescent risk-taking. Dev Rev 2008;28: 78-106.

19 Ernst M, Romeo RD, Andersen SL: Neurobiology of the development of motivated behaviors in adolescence: a window into a neural systems model. Pharmacol Biochem Behav 2009;93:199-211.

20 Casey BJ, Jones RM: Neurobiology of the adolescent brain and behavior: implications for substance use disorders. J Am Acad Child Adolesc Psychiatry 2010;49:1189- 1201

21 Chugani HT, Phelps ME, Mazziotta JC: Positron emission tomography study of human brain functional development. Ann Neurol 1987;22:487-497.

-22 Sowell ER, Thompson PM, Holmes CJ, Jernigan TL, Toga AW: In vivo evidence for postadolescent brain maturation in frontal and striatal regions. Nat Neurosci 1999;2:859861.

23 Shaw P, Kabani NJ, Lerch JP, Eckstrand K, Lenroot R, Gogtay N, Greenstein D, Clasen L, Evans A, Rapoport JL, Giedd JN, Wise SP: Neurodevelopmental trajectories of the human cerebral cortex. J Neurosci 2008;28: 3586-3594.

24 Gogtay N, Giedd JN, Lusk L, Hayashi KM, Greenstein D, Vaituzis AC, Nugent TF 3rd, Herman DH, Clasen LS, Toga AW, Rapoport JL, Thompson PM: Dynamic mapping of human cortical development during childhood through early adulthood. Proc Natl Acad Sci USA 2004;101:8174-8179.

25 Galván A, Hare TA, Parra CE, Penn J, Voss H, Glover G, Casey BJ: Earlier development of the accumbens relative to orbitofrontal cortex might underlie risk-taking behavior in adolescents. J Neurosci 2006;26:6885-6892.
26 Huttenlocher PR: Synaptic density in human frontal cortex - developmental changes and effects of aging. Brain Res 1979;163:195-205.

27 Bourgeois JP, Goldman-Rakic PS, Rakic P. Synaptogenesis in the prefrontal cortex of rhesus monkeys. Cereb Cortex 1994;4:78-96.

28 Rakic P: Synaptic development of the cerebral cortex: implications for learning, memory and mental illness. Prog Brain Res 1994;102: 227-243.

29 Casey BJ, Getz S, Galván A: The adolescent brain. Dev Rev 2008;28:62-77.

30 Hare TA, Tottenham N, Galván A, Voss HU, Glover GH, Casey, BJ: Biological substrates of emotional reactivity and regulation in adolescence during an emotional go-nogo task. Biol Psychiatry 2008;63:927-934.

31 Tottenham N, Tanahka JW, Leon AC, McCarry T, Nurse M, Hare TA, Marcus DJ, Westerlund A, Casey BJ, Nelson C: The NimStim set of facial expressions: judgments from untrained research participants. Psychiatry Res 2009; 168:242-249.

32 Thomas KM, Drevets WC, Dahl RE, Ryan $\mathrm{ND}$, Birmaher B, Eccard $\mathrm{CH}$, Axelson D, Whalen PJ, Casey BJ: Amygdala response to fearful faces in anxious and depressed children. Arch Gen Psychiatry 2001;58:10571063.

33 Herba C, Phillips M: Annotation: development of facial expression recognition from childhood to adolescence: behavioural and neurological perspectives. J Child Psychol Psychiatry 2004;45:1185-1198.

-34 Gross AL, Ballif B: Children's understanding of emotion from facial expressions and situations: a review. Dev Rev 1991;11:368-398.

- 35 Glover GH, Thomason ME: Improved combination of spiral-in/out images for BOLD fMRI. Magn Reson Med 2004;51:863-868.

36 Cox RW: AFNI: software for analysis and visualization of functional magnetic resonance neuroimaging. Comp Biomed Res 1996;29: 162-173.

37 Chen G, Saad ZS, Britton JC, Pine DS, Cox RW: Linear mixed-effects modeling approach to FMRI group analysis. Neuroimage 2013; 73:176-190.

38 Talairach J, Tournoux P: Co-planar Stereotaxic Atlas of the Human Brain: 3-Dimensional Proportional System - an Approach to Cerebral Imaging. New York, Thieme, 1988.

39 Van Leijenhorst L, Zanolie K, Van Meel CS, Westenberg PM, Rombouts SA, Crone EA: What motivates the adolescent? Brain regions mediating reward sensitivity across adolescence. Cereb Cortex 2010;20:61-69.

40 Botvinick M, Nystrom LE, Fissell K, Carter CS, Cohen JD: Conflict monitoring versus selection-for-action in anterior cingulate cortex. Nature 1999;402:179-181.
41 Casey BJ, Thomas KM, Welsh TF, Badgaiyan $\mathrm{R}$, Eccard CH, Jennings JR, Crone EA: Dissociation of response conflict, attentional control, and expectancy with functional magnetic resonance imaging. Proc Natl Acad Sci USA 2002;97:8728-8733.

42 Guitart-Masip M, Huys QM, Fuentemilla L, Dayan P, Duzel E, Dolan RJ: Go and no-go learning in reward and punishment: interactions between affect and effect. Neuroimage 2012;62:154-166

43 Passler MA, Isaac W, Hynd GW: Neuropsychological development of behavior attributed to frontal lobe functioning in children. Dev Neuropsychol 1985;1:349-370.

-44 Enns JT, Cameron S: Selective attention in young children: the relations between visual search, filtering, and priming. J Exp Child Psychol 1987;44:38-63.

45 Ridderinkhof KR, van der Molen MW, Band GP, Bashore TR: Sources of interference from irrelevant information: a developmental study. J Exp Child Psychol 1997;65:315-341.

46 Asato MR, Terwilliger R, Woo J, Luna B: White matter development in adolescence: a DTI study. Cereb Cortex 2010;20:21222131.

47 Liston C, Watts R, Tottenham N, Davidson MC, Niogi S, Ulug AM, Casey BJ: Frontostriatal microstructure modulates efficient recruitment of cognitive control. Cereb Cortex 2006;16:553-560.

48 Nelson EE, Leibenluft E, McClure EB, Pine DS: The social re-orientation of adolescence: a neuroscience perspective on the process and its relation to psychopathology. Psychol Med 2005;35:163-174.

49 Sisk CL, Zehr JL: Pubertal hormones organize the adolescent brain and behavior. Front Neuroendocrinol 2005;26:163-174.

50 D'Unger AV, Land KC, McCall PL: Sex differences in age patterns of delinquent/criminal careers: results from Poisson latent class analyses of the Philadelphia cohort study. J Quant Criminol 2002;18:349-375.

51 Poe-Yamagata E, Butts JA: Female offenders in the juvenile justice system: statistics summary. National Center for Juvenile Justice, 1996.

52 Byrnes JP, Miller DC, Schafer WD: Gender differences in risk taking: a meta-analysis. Psychol Bull 1999;125:367-383.

53 Blakemore SJ: The social brain in adolescence. Nat Rev Neurosci 2008;9:267-277.

54 Nelson EE, Guyer AE: The development of the ventral prefrontal cortex and social flexibility. Dev Cogn Neurosci 2011;1:233-245.

55 Somerville LH, Jones RM, Ruberry EJ, Dyke JP, Glover G, Casey BJ: The medial prefrontal cortex and the emergence of self-conscious emotion in adolescence. Psychol Sci 2013;24: 1554-1562.

56 Roy M, Shohamy D, Wager TD: Ventromedial prefrontal-subcortical systems and the generation of affective meaning. Trends Cogn Sci 2012;16:147-156.
Teens Impulsively React rather than Retreat from Threat
Dev Neurosci 2014;36:220-227 DOI: $10.1159 / 000357755$ 